\title{
SCIENTIFIC REP RTS \\ Publisher Correction: Manipulation of Rat Movement via Nigrostriatal Stimulation Controlled by Human Visually Evoked Potentials
}

Bonkon Koo ${ }^{1}$, Chin Su Koh ${ }^{2}$, Hae-Yong Park ${ }^{3}$, Hwan-Gon Lee ${ }^{4}$, Jin Woo Chang², Seungjin Choi ${ }^{5}$ \& Hyung-Cheul Shin ${ }^{3}$

Scientific Reports 7:2340; doi:10.1038/s41598-017-02521-6; Article published online 24 May 2017.

In the original version of this Article, Jin Woo Chang was incorrectly listed as being affiliated with 'School of Interdisciplinary Bioscience and Bioengineering, POSTECH, Pohang, Korea.

The correct affiliation is listed below:

Department of Neurosurgery, Yonsei University College of Medicine, Seoul, South Korea.

This error has now been corrected in the HTML and PDF versions of the Article.

(i) Open Access This article is licensed under a Creative Commons Attribution 4.0 International License, which permits use, sharing, adaptation, distribution and reproduction in any medium or format, as long as you give appropriate credit to the original author(s) and the source, provide a link to the Creative Commons license, and indicate if changes were made. The images or other third party material in this article are included in the article's Creative Commons license, unless indicated otherwise in a credit line to the material. If material is not included in the article's Creative Commons license and your intended use is not permitted by statutory regulation or exceeds the permitted use, you will need to obtain permission directly from the copyright holder. To view a copy of this license, visit http://creativecommons.org/licenses/by/4.0/.

(c) The Author(s) 2017

${ }^{1}$ School of Interdisciplinary Bioscience and Bioengineering, POSTECH, Pohang, Korea. ${ }^{2}$ Department of Neurosurgery, Yonsei University College of Medicine, Seoul, South Korea. ${ }^{3}$ Department of Physiology, College of Medicine, Hallym University, Chuncheon, Korea. ${ }^{4}$ Department of Physical Education, Hallym University, Chuncheon, Korea. ${ }^{5}$ Department of Computer Science and Engineering, POSTECH, Pohang, Korea. Bonkon Koo and Chin Su Koh contributed equally to this work. Correspondence and requests for materials should be addressed to H.-C.S. (email: hcshin@hallym.ac.kr) 